\title{
Artigo
}

\section{O PROFESSOR E OS DESAFIOS NO ENSINO DA LÍNGUA PORTUGUESA PARA SURDOS}

\author{
THE TEACHER AND THE CHALLENGES IN TEACHING THE PORTUGUESE \\ LANGUAGE TO THE DEAF \\ EL PROFESOR Y LOS DESAFÍOS EN LA ENSEÑANZA DEL LENGUA \\ PORTUGUESA A LOS SORDOS
}

\author{
Kátia Quele Ferreira da Silva Rocha \\ Ludmila Borges Lira e Silva
}

\begin{abstract}
Resumo
O presente artigo visa discutir a importância da Língua Brasileira de Sinais- Libras, para o processo e de ensino aprendizagem dos alunos surdos, e como esta língua, deveria ser usada nas salas de aulas regulares, com enfoque nas aulas de língua portuguesa como segunda língua. É importante compreender, que há dificuldades encontradas por professores ouvintes e pelo aluno surdo no processo de inclusão, uma vez que o veículo de comunicação é a língua e nesse caso não é de domínio da maioria. Diante disso que surge o desejo de investigar como esses professores têm vencidos esses desafios para de forma satisfatória ajudar esses alunos. Foi realizada uma pesquisa bibliográfica qualitativa, com teóricos como Quadros, Mantoan e Freire, a fim de discutir a realidade de sala de aula com a visão teórica. Sabe-se que a educação de qualidade é um direito de todos, garantido por Lei, porém ainda não é um fato concretizado e é necessário buscar, discutir e refletir na luta para que se torne realidade.
\end{abstract}

\begin{abstract}
This article aims to discuss the importance of the Brazilian Sign Language for the deaf students' learning process and teaching, and how this language should be used in regular classrooms, focusing on Portuguese as a second language classes. It is important to understand that there are difficulties encountered by hearing teachers and the deaf student in the inclusion process, since the vehicle of communication is the language and in this case it is not the domain of the majority. Faced with this is the desire to investigate how these teachers have overcome these challenges to satisfactorily help these students. A qualitative bibliographic research was conducted, with theorists such as Quadros, Mantoan and Freire, in order to discuss the reality of the classroom with the theoretical view. It is known that quality education is a right of all, guaranteed by law, but is not yet a fact and it is necessary to seek, discuss and reflect on the struggle to make it a reality.
\end{abstract}

\section{Resumen}

Este artículo tiene como objetivo discutir la importancia del lenguaje de señas brasileño - Libras, para el proceso y el aprendizaje de la enseñanza de los estudiantes sordos, y cómo este idioma debe usarse en las aulas regulares, centrándose en el portugués como segundo idioma. . Es importante comprender que los maestros que escuchan y el alumno sordo encuentran dificultades en el proceso de inclusión, ya que el vehículo de comunicación es el idioma y, en este caso, no es el dominio de la mayoría. Ante esto, surge el deseo de investigar cómo estos maestros han superado 
estos desafíos para ayudar satisfactoriamente a estos estudiantes. Se realizó una investigación bibliográfica cualitativa, con teóricos como Quadros, Mantoan y Freire, para discutir la realidad del aula con una visión teórica. Se sabe que la educación de calidad es un derecho para todos, garantizado por la ley, pero aún no es un hecho concreto y es necesario buscar, debatir y reflexionar sobre la lucha para hacerla realidad.

Palavras-chave: Libras; Língua Portuguesa; Ensino-aprendizagem.

Keywords: Libras; Portuguese language; Teaching-learning.

Palabras claves: Libras; Lengua portuguesa; Enseñanza - aprendizaje.

\section{INTRODUÇÃO}

O pensamento da inclusão das pessoas com necessidades educacionais específicas na escola regular, tem se fortalecido cada vez mais, com a proposta assinada na declaração de Salamanca (1994), veio reafirmando que as ações pedagógicas, além de possuir as características democráticas, deverá ser pluralista, não garantindo apenas o acesso, mas a permanência do aluno nos diversos níveis de ensino e respeitando fundamentalmente sua identidade social, ressaltando que as diferenças são normais e a escola deverá considerar essas múltiplas diferenças, promovendo as adaptações necessárias, que atendam as necessidades de aprendizagem de cada educando no processo educativo, como destaca a LDB (Lei de Diretrizes e Bases, artigo 59, capítulo V) "Os sistemas de ensino assegurarão aos educandos com necessidades especiais: Currículos, métodos, técnicas, recursos educativos e organização específica, para atender às suas necessidades".

Inseridos neste processo de educação inclusiva estão os sujeitos surdos, estes que buscam cada vez mais o reconhecimento de sua cultura e identidade, e lutam pelas escolas bilíngues, onde o acesso ao conhecimento chegaria a eles de maneira mais completa, sem fragmentação, permitindo melhores resultados nos rendimentos escolares, porém enquanto as escolas bilíngues não são realidades em todos os lugares, os alunos surdos são inseridos nas salas regulares e superam todos os dias suas dificuldades para garantirem o processo de construção de conhecimentos .

As dificuldades que esses estudantes passam nas salas de aula regulares muitas vezes estão relacionadas a falta de comunicação, as relações entre e professores e alunos surdos ou aluno surdo com colega ouvinte nem sempre se estabelecem completamente, isso dificulta o aprendizado desse sujeito, partindo dessa inquietação quais metodologias tem funcionado no ensino os alunos surdos? Existem estratégias que facilite o trabalho dos professores que lidam com o ensino desses alunos?

Pensando assim, se faz necessário investigar o papel do professor no processo de aquisição da aprendizagem do surdo, discutir sobre as dificuldades que enfrentam ao trabalhar com esse público, e as possíveis metodologia para auxiliá-los, e refletir como se dá essa relação entre professor e aluno surdo, uma vez que a barreira da língua compromete o real aprendizado.

A educação tem um papel fundamental para o desenvolvimento de indivíduos críticos e conscientes de ser cidadão atuante na sociedade em todos 
os seus âmbitos, estar inserido no espaço escolar é direito de todos para ali construir relações de valores e respeito. Essa é uma das lutas que muitas comunidades surdas enfrentam atualmente, a busca pela construção igualitária de conhecimentos onde a comunicação fluente é a principal base de acessibilidade.

A partir da visão de que o aluno surdo tem seus direitos garantidos ao real acesso à educação, e de que na prática as metodologias didáticas utilizadas em salas de aula, muitas vezes não condizem com a realidade deste sujeito, surge o interesse de pesquisar uma metodologia de ensino que venha auxiliar e facilitar o processo de ensino aprendizagem desses educandos, levando em consideração que muitos professores não recebem formação para trabalhar como os alunos Surdos.

A escolha do objeto de pesquisa deu-se pelas inquietações discutidas sobre as dificuldades encontrados por professores ao lidarem com alunos surdos inseridos nas classes regulares com idades diversas, alguns desses alunos com aquisição tardia da Libras, apresentam grandes dificuldades em relação a leitura e escrita da língua portuguesa, e os professores não sabem como auxiliar esses educandos a sanar essa dificuldade justamente por conta do entrave da falta de comunicação e domínio da língua de sinais, diante disso despertou o interesse em compreender de que forma a prática pedagógica pode ser repensada para contribuir de forma significativa no processo ensino aprendizagem desses alunos.

A formação acadêmica em Letras faz perceber a complexidade de se aprender o português, respeitando as regras e os conceitos pertencentes a esta língua, aos docentes cabem compreender que esse processo não deve acontecer apenas como deposito de conteúdos com informações vagas, é preciso significação, como aponta Freire (1996), o discente precisa também formar-se,

É preciso que, pelo contrário, desde os começos do processo, vá ficando cada vez mais claro que, embora diferentes entre si, quem forma se forma e reforma ao formar e quem é formado forma-se e forma ao ser formado. É neste sentido que ensinar não é transferir conhecimentos, conteúdos nem formar é ação pela qual um sujeito criador dá forma, estilo ou alma a um corpo indeciso e acomodado. Não há docência sem discência, as duas se explicam e seus sujeitos, apesar das diferenças que os conotam, não se reduzem à condição de objeto, um do outro. Quem ensina aprende ao ensinar e quem aprende ensina ao aprender. Quem ensina, ensina alguma coisa a alguém. Por isso é que, do ponto de vista gramatical, o verbo ensinar é um verbo transitivo-relativo. (Freire, 1996 p. 12)

Portanto faz-se importante investigar quais metodologias podem funcionar para garantir a aprendizagem do educando surdo no tange as competências da Língua Portuguesa, uma vez que esta sua segunda língua e eles fazem parte da sociedade que a população majoritária é fluente nesta língua e o surdo depende dessas habilidades para se comunicar melhor. Entende-se que essa análise irá ampliar o entendimento do pesquisador para o trato com a realidade do ensino de alunos surdos. 


\section{DESENVOLVIMENTO}

Dentro dessa área de educação inclusiva, torna-se como objeto de estudo para esta pesquisa o trabalho com os alunos surdos, enfatizando os desafios vivenciados diariamente por parte de educandos e educadores nesse processo de construção de aprendizagem. Para se trabalhar com estudantes surdos é necessário que os educadores estejam preparados para atender com excelência as suas especificidades, para que se promova a aprendizagem dos alunos com eficiência, Segundo Gesser :

Para dar conta das questões educacionais na formação do surdo, inclusive a aprendizagem da língua Portuguesa em sua modalidade escrita, há a necessidade de inverter a lógica praticada até então nos ambientes escolares e afirmar; "Os professores ouvintes de crianças surdas é que precisam saber a LIBRAS para poderem educá-las. (GESSER, 2009, p. 60)

Está inserido no meio educacional é um desafio muito grande para os estudantes surdos que lutam cada vez por seus direitos de igualdade, neste meio tão competitivo e desigual. O papel do professor como mediador do ensino e motivador da aprendizagem é fundamental, este pode ser marcante para toda vida do estudante, Paulo Freire (1996) defende que a "educação deve ser libertadora", esta tem a funcionalidade de tornar o estudante um sujeito crítico e pensante, atuante na sociedade em que está inserido.

\section{Os desafios da educação para alunos surdos}

O surdo vive o desafio constante de ser aceito pela sociedade majoritariamente ouvintista com suas especificidades, tendo que mostrar que é capaz de estar lado a lado de forma igual aos ouvintes, o que vemos na realidade é a falta de oportunidades para estes sujeitos.

Os (as) alunos (as) Surdos (as), quando perguntados (as) sobre como se sentiam estudando com os (as) ouvintes, quase a totalidade deles (as) afirmou que tal situação exige muito sacrifício, paciência e esforço, o que se contrapõe ao objetivo fundamental da educação inclusiva, de acolher todas as diferenças em ambientes que proporcionem uma educação de qualidade para todos (as) (PEDREIRA, 2007, p. 3).

E esses dilemas apresentam- se também dentro das salas de aulas onde as dinâmicas de ensino são voltadas apenas para comtemplar os ouvintes, por ser maioria na classe, um erro que segundo a Lei 9.394/96 que aponta os princípios educacionais defende como direito do cidadão o seu ensino de forma plena, e para isso os métodos de se lidar com sujeito surdo deve ser repensado com urgência. A relação de interação entre professor e aluno é de suma importância no processo da construção da aprendizagem, esta define de que forma positiva ou negativa ocorre esta formação, Piaget em estudos fala sobre a importância da interação com o meio em que se está 
inserido para o processo de aprendizagem, Nunes e Silveira (2008) ao citar Piaget confirmam,

Segundo Piaget, a evolução do conhecimento é um processo continuo construído a partir da interação ativa do sujeito com o meio (físico e social). O desenvolvimento humana passa por estágios sucessivos de organização do campo cognitivo e afetivo, que vão sendo construídos em virtude da ação da criança e das oportunidades que 0 ambiente possibilita a mesma. (NUNES; SILVEIRA, 2008,p.82)

Em se tratando do educando surdo, essa relação nem sempre se dá, pois a maioria dos professores regentes não conhecem a Libras, que é a língua de instrução do surdo, passando a responsabilidade aos profissionais tradutores/intérpretes de Libras e Língua Portuguesa-TISLP e deixando os surdos por vezes segregados, vivenciando uma falsa inclusão na sala de aula. Nas salas regulares as aulas são ministradas visando a maioria, ou seja, diálogos orais e atividades escritas em livros didáticos com enfoque só a leitura, sem nenhuma metodologia visual para comtemplar o aluno surdo e suas especificidades. Fica claro a exclusão já no planejamento, pois não se pensa em nada para incluir esse sujeito, como consequência, resulta em grande dificuldade de comunicação por falta de uma Língua que os una.

(...) o ensino da língua portuguesa para crianças surdas, principalmente em escolas regulares, não tem considerado este fato e as crianças surdas, inseridas em classes de crianças ouvintes recebem o mesmo tipo de atividade como se já tivessem adquirido esta língua naturalmente e tivessem 0 mesmo desempenho das ouvintes. (FELIPE, 1997, p. 41).

A situação é que muitos professores não receberam capacitação adequada ou buscam se atualizarem acerca da necessidade educacional especial deste aluno, uma vez que pensando no ensino público estes tem direitos a serem capacitados com até auxilio do governo, mas o que não justifica a falta de interesse desses profissionais de buscar o preparo necessário para atuarem junto a estes estudantes, o Decreto de Lei no 5.626 de 22 de dezembro de 2005, em seu artigo $3^{\circ}$ apresenta que,

A Libras deve ser inserida como disciplina curricular obrigatória nos cursos de formação de professores para 0 exercício do magistério, em nível médio e superior, e nos cursos de fonoaudiologia, de instituições de ensino, públicas e privadas, do sistema federal de ensino e dos sistemas de ensino dos Estados, do Distrito Federal e dos Municípios.

Não se pode pensar no ensino de língua portuguesa para surdos desassociado do ensino de Libras. Vale salientar que os alunos surdos são inseridos nas classes regulares de ensino e no turno oposto recebem atendimento específico da Libras na classe especial, o que se torna apenas um apoio pedagógico, porém a comunidade surda vem lutando para que seja implantada a proposta bilíngue nas escola brasileiras que garante ao aluno 
surdo o seu primeiro momento de aprendizado com sua primeira língua que no caso é a Libras, Quadros (1997) afirma que nessa luta pelo bilinguismo, mesmo que recente algumas conquistas já podem ser vistas como,

O reconhecimento da pessoa surda enquanto cidadã integrante da comunidade surda com o direito de ter assegurada a aquisição da língua de sinais como primeira língua; o uso da língua de sinais na escola para garantir o desenvolvimento cognitivo e o ensino de conhecimentos gerais; o ensino da língua oral-auditiva com estratégias de ensino de segunda língua e a inclusão de pessoas surdas nos quadros funcionais das escolas. (Quadros, 1997, p.40)

É fato que a grande maioria das crianças surdas tem seu intelecto preservado, e com capacidades de aprendizagem iguais aos dos ouvintes, porém sem os estímulos iniciais necessários como a que todas as crianças são submetidas, elas terão dificuldade em aprender e poderá até afastar-se do convívio social, tendo reflexos negativos em sua vida futura.

\section{O que é a Libras e como esta pode ser usada no processo de ensino aprendizagem do surdo}

A língua é o principal veículo de comunicação dos sujeitos de uma determinada sociedade. Por ela os indivíduos se expressam, refletem e criticam expondo suas opiniões, faz parte da linguagem, como define Saussure:

[...]Para Saussure, é impossível descobrir a unidade da linguagem. Por isso, ela não pode ser estudada como uma categoria única de fatos humanos. A língua é diferente. Ela é uma parte bem definida e essencial da faculdade da linguagem. Ela é um produto social da faculdade da linguagem e um conjunto de convenções necessárias, estabelecidas e adotadas por um grupo social para o exercício da faculdade da linguagem. A língua é uma unidade por si só. Para Saussure, ela é a norma para todas as demais manifestações da linguagem. Ela é um princípio de classificação, com base no qual é possível estabelecer uma certa ordem na faculdade da linguagem (SAUSSURE, 1916).

A língua de sinais é a primeira língua dos surdos, pode-se afirmar isso, levando em consideração que o sujeito quando nasce surdo, não tem nenhum contato com sons audíveis, então sua comunicação acontece por meio de gestos, os chamados sinais caseiros, estabelecidos primeiramente com a família, por meio destes gestos eles vão estabelecendo suas relações com os sujeitos que convivem, com muita dificuldade para serem compreendidos. Essas angustias só vão se aliviando quando esses surdos se encontram com as línguas de sinais, e percebem que podem se comunicar com mais clareza, encontram nela uma ferramenta indispensável para conviver em sociedade, portanto a língua de sinais é a língua natural do surdo, SKLIAR esclarece bem essa aquisição ao dizer que, 
Todas as crianças surdas podem adquirir a língua de sinais, desde que participem das interações cotidianas com a comunidade surda, como acontece com qualquer outra criança na aquisição de uma língua natural. "Natural", entretanto, não se refere a uma certa espontaneidade biológica. Língua natural, aqui, deve ser entendida como uma língua que foi criada e é utilizada por uma comunidade específica de usuários, que se transmite de geração em geração, e que muda tanto estrutural como funcionalmente com o passar do tempo (SKLIAR, 1998).

A Libras é uma língua, viva, faz parte de uma sociedade e possui usuários, é considerada por Quadros (2004) como uma língua natural:

As línguas de sinais são consideradas línguas naturais e consequentemente compartilham uma série de características que lhes atribui caráter especifico e as distingue dos demais sistemas de comunicação conforme discutido anteriormente.

As línguas de sinais são, portanto, consideradas pela linguística como línguas naturais ou como um sistema linguístico legitimo e não como um problema do surdo ou como uma patologia da linguagem. (Quadros, 2004, pág. 30)

As línguas de sinais, assim como a Libras, são línguas de modalidade gestual-visual, ou seja explora o principal canal do surdo, o campo de visão, e realiza no espaço, onde os sinais são construídos viabilizando a comunicação entre os indivíduos. Possui gramática própria, e níveis linguísticos, fonológico, morfológico, semântico, sintático e pragmático, para Salles,

A LIBRAS é dotada de uma gramática constituída a partir de elementos Constitutivos das palavras ou itens lexicais e de um léxico que se estruturam a partir de mecanismos fonológicos, morfológicos, sintáticos e semânticos que apresentam também especificidades, mas seguem também princípios básicos gerais. É adotada também de componentes pragmáticos convencionais codificados no léxico e nas estruturas da LIBRAS e de princípios pragmáticos que permitem a geração de implícitos sentidos metafóricos, ironias e outros significados não literais. A LIBRAS é a língua utilizada pelos surdos que vivem em cidades do Brasil, portanto não é uma língua universal. (Salles, 2004, pág.212)

As línguas de sinais se apropriam também das expressões faciais e corporais, usadas para dar sentido e forma às frases, como as entonações existentes na Língua Portuguesa, pois os sinais são feitos através da combinação do movimento das mãos em um determinado ponto, chamado ponto de articulação que se dá geralmente em um quadrado imaginário que delimita o espaço em frente ao corpo da pessoa que está falando em Libras, Quadros (2004), denomina essas unidades mínimas como parâmetros primários e secundários que formam uma parte da estrutura desta Língua.

Para garantir uma aquisição significativa dos conhecimentos e produção de aprendizagem, faz-se necessário que a Língua de sinais seja incorporada 
ao currículo das instituições educacionais, pois é evidente que só por meio dela esses indivíduos alcançarão plena aprendizagem.

\section{O professor e o aluno surdo}

Sabe-se que para ocorrer o processo de ensino, um sujeito indispensável é o educador, porém sem o aluno a aula não acontece. Professores e alunos são personagens principais na sala de aula, para ocorrer o processo de ensino aprendizagem, é imprescindível a boa relação entre essas partes, como afirma Freire ao dizer que,

Não há docência sem discência, as duas se explicam e seus sujeitos, apesar das diferenças que os conotam, não se reduzem à condição de objeto, um do outro. Quem ensina aprende ao ensinar e quem aprende ensina ao aprender. (FREIRE, 1996, p.32)

Nesse sentido a prática do professor deve estar voltada para situações estimulantes através de aulas dinâmicas, descontraídas, que sejam atrativas ao educando, utilizando metodologias didáticas adequadas, para mediar positivamente o processo educacional, Libãneo afirma que,

O professor medeia à relação ativa do aluno com a matéria, inclusive com os conteúdos próprios de sua disciplina, mas considerando o conhecimento, a experiência e o significado que o aluno traz à sala de aula, seu potencial cognitivo, sua capacidade e interesse, seu procedimento de pensar, seu modo de trabalhar. (LIBÂNEO 1998, p.29)

Didática é uma parte das ciências pedagógicas que tem como objetivo principal ensinar métodos e técnicas que possibilitam a aprendizagem do aluno são ferramentas de uso do professor para proporcionar uma aula produtiva, ou seja, onde aconteça de fato o processo ensino-aprendizagem. Está baseada em teorias pedagógicas que analisam métodos mais adequadas que favoreça a prática, assim o ensino de Língua Portuguesa para os alunos precisa ser repensado, Pereira bem coloca que,

Com base na concepção discursiva de língua, o objetivo no ensino da Língua Portuguesa para os alunos surdos, como para os alunos ouvintes, deve ser a habilidade de produzir textos e não palavras e frases, daí a importância de se trabalhar muito bem o texto, inicialmente na Língua Brasileira de Sinais. Para isso cabe ao professor traduzir os textos ou partes deles para a língua de sinais e vice-versa, bem como explicar e esclarecer aspectos sobre a construção dos textos. As explicações devem ser dadas numa perspectiva contrastiva, na qual as diferenças e as semelhanças entre a Língua Brasileira de Sinais e a Língua Portuguesa sejam elucidadas. Desta forma, os alunos vão observar como uma mesma ideia é expressa nas duas línguas. Esta prática serve de base para os alunos formularem suas hipóteses sobre o funcionamento das duas línguas. (PEREIRA 2014, p. 149) 
Um bom professor procura realizar suas aulas bem planejadas, transmiti os conteúdos de maneira clara, levando seu educando a ser ativo e participativo, estabelece uma boa relação de convivência para criar um ambiente de troca de experiências e saberes, o olhar do professor para o surdo deve ser mais sensível, deve explorar o campo visual e levar em consideração suas especificidades, como aponta Damázio,

As práticas pedagógicas constituem o maior problema na escolarização das pessoas com surdez. Torna-se urgente, repensar essas práticas para que o aluno com surdez, não acreditem que suas dificuldades para domínio da leitura e da escrita são advindas dos limites que a surdez lhes impõe, mas principalmente pelas metodologias adotadas para ensiná-los. (DAMÁZIO, 2007 p.21)

O trabalho educacional com alunos surdos deve ser diferenciado, os educadores envolvidos no processo de ensino desses sujeitos devem repensar suas práticas pedagógicas na tentativa de promover real aprendizagem nesses indivíduos, os quais devem ser vistos como diferentes, não deficientes, o olhar do educador deve estar na maneira como o surdo aprende, e para tanto em alguns momentos os métodos de ensino deverão ser revistos, como bem afirma Marilia Silva,

é necessário enfatizar que as condições de aprendizagem da leitura e da escrita no processo de escolarização do aluno surdo dependem por via de regra do modo pelo qual são encaradas suas dificuldades e as diferenças ocorridas no processo educacional pelas instituições, levando-o a adquirir confiabilidade nas dificuldades encontradas. Nessa mesma ótica é preciso destacar que o surdo, antes de ter dificuldades na escola apresenta dificuldades de aquisição da língua, estalando-se a grande diferença de escolarização entre o surdo e o ouvinte. (SILVA 2001, p. 43 e 44)

Para que o conhecimento seja construído de maneira autônoma o estudante deve se sentir motivado e confiante, certo de que é capaz para superar os desafios propostos e construir suas próprias respostas e reflexões, Freire afirma que a educação só e significativa quando este educando caminha sozinho, e este estimular parte de seu educador que não deve negligenciar as especificidades de cada educando, ele diz que,

O professor que desrespeita a curiosidade do educando, o seu gosto estético, a sua inquietude, a sua linguagem, mais precisamente, a sua sintaxe e a sua prosódia; o professor que ironiza o aluno, que o minimiza, que manda que "ele se ponha em seu lugar" ao mais tênue sinal de sua rebeldia legítima, tanto quanto o professor que se exime do cumprimento de seu dever de ensinar, de estar respeitosamente presente à experiência formadora do educando, transgredi os princípios fundamentalmente éticos de nossa existência. (FREIRE 1996, p. 59-60) 
Sabe-se que para muitos o trabalho com estudantes surdo não é muito fácil, um dos grandes desafios do professor é lidar com a falta de capacitação, o que leva o contato com professor regente e aluno surdo, acontecer de forma fria e distante, Infelizmente pesquisas revelam que a maioria dos professores regentes de classes, são despreparados para lidar com essa demanda, e não possuem conhecimento algum sobre Libras, deixando a responsabilidade do ensino apenas na mãos dos intérpretes, sabendo que este não é o papel deste profissional, porém o rendimento seria maior se o professor regente se enxergasse como agente fundamental e transformador na vida desse aluno.

Assim, os saberes legitimados pela formação de professores refinam o investimento de poder operado pelas instituições escolares, constituindo-se, nessa engrenagem, como uma estratégia de enquadramento dos sujeitos, especialmente em razão da necessidade de produzir alunos e professores dóceis, maleáveis, administráveis. Nessa paisagem em que se torna indispensável formar um determinado corpo de experts e colocar determinadas práticas em funcionamento, a educação especial constitui-se como uma expertise, um aparato de saber pedagógico emergente no contexto da modernidade para equacionar e continuar produzindo os estranhos - entre eles, os surdos - necessários à dinâmica de ordenamento dessa racionalidade (MACHADO; LUNARDI- LAZZARIN, 2010, p. 23).

Se tratando do ensino para Surdos, o planejamento deve ser voltado para praticas visuais, por este ser o canal principal de entrada das informações externas para estes sujeitos. O educador deve levar em consideração que explorando a parte visual ele irá promover no surdo um aprendizado mais significativo, vídeos podem ser utilizados, jogos da memória com ilustrações, para fixar assuntos complexos, salientando que a ludicidade é favorável no processo de ensino-aprendizagem, interessante também será o uso da língua de sinais que a língua do surdo, explora-la de forma criativa irá auxiliar o surdo, a exemplo do uso dos movimentos e expressões faciais para trabalhar texto, desenvolvendo habilidades artísticas que são natas na maioria destes sujeitos.

O ensino bilíngue preconiza que o surdo deve ser exposto, o mais precocemente possível, a sua língua natural, identificada como uma língua passível de ser adquirida por ele sem que sejam necessárias condições especiais de aprendizagem. Que também seja ensinada, ao surdo, a língua da comunidade ouvinte na qual está inserido em sua modalidade oral e/ou escrita, sendo que esta será ensinada com base nos conhecimentos adquiridos por meio da língua de sinais (LACERDA, 2000).

Explorando as especificidades do aluno Surdo, o educador fará com este sinta-se aceito, querido e reconhecido, dessa forma estarão motivados a continuarem na escola, pois a enxergam como sendo também um ambiente seu. Portanto, para que aconteça, de fato, a inclusão escolar, devem acontecer mudanças e adaptações que atinjam a todos e não apenas aos educandos 
especiais, pois, direta ou indiretamente, fazem parte da vida escolar desses alunos, no que diz respeito a esses procedimentos, Jesus (2004) afirma que:

As escolas que queiram responder a este desafio contra a exclusão, criando uma nova escola em que todos os alunos sem exceção possam desenvolver ao máximo as suas competências, terão de implantar novos modelos pedagógicos de cooperação e diferenciação, entende-se por diferenciação o processo através do qual os professores conduzam os alunos a progredir no currículo, através de uma relação adequada de métodos de ensino e estratégias de aprendizagem e de estudo. (Jesus, 2004, p. 75)

As escolas inclusivas devem criar meios para que se valorize a diversidade num âmbito geral, construindo assim o respeito e a colaboração por parte de todos, especialmente dos alunos que convivem juntos. Deve-se adequar materialmente e pedagogicamente, assegurando uma produção de conhecimento igual para todos, ocasionando uma mudança de pensamento e atitudes por parte de todos os envolvidos no processo educacional. É o que, segundo Martins (2006, p. 20) trata-se de "uma pedagogia centrada no aluno que por sua vez, suscite a construção de uma sociedade que respeite a dignidade e as diferenças humanas.

\section{PROCEDIMENTOS METODOLÓGICOS}

Pesquisar é um ato que exige planejamento, partindo dessa premissa, para garantir o bom desenvolvimento da pesquisa, faz necessária a observação do método escolhido, pois tais procedimentos determinarão o sucesso deste trabalho, adotar uma metodologia significa e escolher o caminho certo e prático para alcançar o objetivo desejado.

É pertinente pensar numa metodologia para está pesquisa que seja de natureza descritiva, com objetivos de observar e levantar opiniões sobre o objeto de estudo, o método de procedimento realizado será qualitativo, de cunho bibliográfico dialogando com os teóricos que tratam do assunto. Nessa proposta de trabalho realizar-se-á uma pesquisa qualitativa respeitando seus aspectos processuais, enfatizando os conceituais, dialogando com os teóricos aderidos, como afirma Godoy,

A pesquisa qualitativa não procura enumerar e/ou medir os eventos estudados, nem emprega instrumental estatístico na análise dos dados, envolve a obtenção de dados descritivos sobre pessoas, lugares e processos interativos pelo contato direto do pesquisador com a situação estudada, procurando compreender os fenômenos segundo a perspectiva dos sujeitos, ou seja, dos participantes da situação em estudo (GODOY, 1995, p. 58).

Nessa abordagem qualitativa, propõe-se a autora a fazer as leituras necessárias com o intuito de identificar as principais dificuldades enfrentadas por alunos surdos dentro das salas de aulas regulares e conhecer quais métodos os professores que atuam com o ensino desses alunos tem dado 
certo, para isso faz-se necessário estudar as leis que tratam do assunto e alguns pesquisadores que trazem em seus estudos orientações e embasamento para atuar melhor junto a estes educandos, e a partir dessas leituras construir analises necessárias para o desenvolvimento do trabalho, finalizar com o relatório descritivo.

\section{RESULTADOS E DISCUSSÃO}

As práticas pedagógicas utilizadas pelos docentes nos ambientes escolares não tem atendido as demandas das pessoas com surdez, diante de toda problemática, caracterizada no sistema educacional voltada para as pessoas com necessidades educacionais específicas, sobre tudo com surdez, conclui-se que há uma necessidade urgente, de repensar essas práticas pedagógicas, para adequar uma boa qualidade de ensino para essas crianças, afim de que ocorra de fato a inclusão desses alunos e que não sejam, somente inseridas em salas de aula, ou seja, esse público, da qual falamos, precisam receber o apoio necessário de acordo com a Lei. As práticas aplicadas atualmente, são defasadas e contribuem para dificuldade de domínio da leitura e da escrita das pessoas com surdez, muitas vezes fazendo a entender que são limitações que as pessoas com surdez impõem, más, no entanto são deficiência do conjunto de profissionais que atuam na área educacional.

O atendimento didático - pedagógico para os alunos com surdez incluídos na escola comum implica o uso de muitas imagens visuais e de todo tipo de referências que passam a colaborar para o aprendizado dos conteúdos curriculares em estudo, na sala de aula comum (DAMAZIO, 2007, p. 26).

As metodologias são adotadas para inserir o discente na sala de aula e auxilia-lo no processo de aprendizagem, quando esse método não é adequado ao público, este consequentemente não avança, essa situação é frequente na vida dos surdos, pois a maior parte dos docentes não é capacitada na língua destes alunos.

A maior queixa do professores foi exatamente a dificuldade em comunicar-se com seus alunos, diziam sentir frustrados em não conseguirem desenvolver um diálogo mais longo, com entendimento, estando sempre dependentes dos interpretes, alguns se mostram interessadas em fazer cursos de Libras, ou se aprofundar mais no conhecimento da língua, porém se esbarram em muitas dificuldades sejam financeiras ou de logísticas de tempo.

Os professores devem demostrar a finalidade das suas disciplinas es conteúdos nelas estudado buscando adequar os assuntos abordados com os conhecimentos prévios a vivencia que os alunos trazem para o espaço escolar, como afirma Libâneo,

Que o professor modela a relação ativa do aluno com a matéria, inclusive com os conteúdos próprios de sua disciplina, mas considerado o conhecimento, a experiência e o significado que o aluno traz à sala de aula, seu potencial cognitivo, sua 
capacidade e interesse, seu procedimento de pensar, seu modo de trabalhar. (LIBÂNEO, 1998, p.29)

Os alunos surdos desejam adquirir conhecimentos de forma significativa, porém enfrentam diversos problemas dentro das salas de aulas regulares. 0 principal se dá com a falta de comunicação, pois a língua é o principal meio de comunicação e mediação da aprendizagem entre professor e aluno. Na maioria das vezes os professores regentes não conhecem a Libras (Língua Brasileira de Sinais), e acabam por deixar os alunos sob a responsabilidade dos intérpretes, que se tornam os únicos mediadores do ensino e convivência dos surdos nas salas regulares, conforme demonstra Quadros (2004):

O intérprete especialista para atuar na área da educação deverá ter um perfil para intermediar as relações entre os professores e os alunos, bem como, entre os colegas surdos e os colegas ouvintes. No entanto, as competências e responsabilidades destes profissionais não são tão fáceis de serem determinadas. Há vários problemas de ordem ética que acabam surgindo em função do tipo de intermediação que acaba acontecendo em sala de aula. Muitas vezes, o papel do intérprete em sala de aula acaba sendo confundido com o papel do professor. Os alunos dirigem questões diretamente ao intérprete, comentam e travam discussões em relação aos tópicos abordados com o intérprete e não com o professor. 0 próprio professor delega ao intérprete a responsabilidade de assumir o ensino dos conteúdos desenvolvidos em aula ao intérprete. Muitas vezes, o professor consulta o intérprete a respeito do desenvolvimento do aluno surdo, como sendo ele a pessoa mais indicada a dar um parecer a respeito. $O$ intérprete, por sua vez, se assumir todos os papéis delegados por parte dos professores e alunos, acaba sendo sobrecarregado e, também, acaba por confundir o seu papel dentro do processo educacional, um papel que está sendo constituído. (QUADROS, 2004, p. 60)

O que os alunos surdos mais se queixa é exatamente esse distanciamento que sentem em relação aos professores e colegas, e desejam que medidas sejam criadas e efetivadas para favorecer seu aprendizado. Os estudantes surdos querem mudar essa realidade e buscam estar inseridos verdadeiramente em suas salas de aula, por isso lutam para que haja uma inclusão verdadeira, segundo Carvalho (2004), educação inclusiva é:

Igualdade de oportunidades, respeito ás necessidades individuais, melhoria na qualidade do processo ensinoaprendizagem (respostas educativas das escolas), melhoria das condições de trabalho dos educadores, maior participação das famílias e da sociedade em geral, remoção de barreiras para aprendizagem e para participação... são outros princípios que dever ser seguidos para colocar-se em prática o que se concebe como sistemas educacionais inclusivos. (Carvalho 2004, p.79) 
É preciso uma mudança de olhar, um pensamento mais reflexivo em prol das questões linguísticas que envolve os surdos, pensar em estratégias de ensino utilizadas necessitam contemplar o potencial cognitivo levando-se em consideração suas possibilidades, competências, raciocínio e percepção, facilitando o processo de ensino e aprendizagem.

\section{CONSIDERAÇÕES FINAIS}

A importância da disseminação da cultura surda através da língua brasileira de sinais enriquece a comunicação, favorecendo de fato a inclusão desse público no meio social, uma vez que o grande problema vivenciado pelos surdos são os ambientes sociais sem ninguém para viabilizar a comunicação tendo este sempre que está acompanhado de seus intérpretes amigos e familiares sem as vezes ter a oportunidade de demonstrar sua autonomia.

Realizar esta pesquisa permitiu fazer uma reflexão sobre a inclusão de pessoas com necessidades educacionais especiais na sociedade e de modo específico na comunidade surda, que vem sendo alvo de debates e discussões, pois no momento é visível uma inserção nos ambientes escolares, e no meio social, apenas para driblar as leis e decretos que as amparam.

Discutir sobre os desafios dos professores levou-se a perceber que as metodologia deve ser adequada para que atendam as demandas necessárias do aluno surdo e para isto ocorrer os profissionais deve buscar mudanças, adaptações estratégias que iram auxiliar seus alunos no ato de aprender, ser capacitados na área especifica nem sempre é possível, porém o profissional deve buscar anseiar por qualificação, vinda ou não da instituição que atua, é preciso dar suporte necessário para haja êxito nas estratégias metodológicas, priorizando o visual, as imagens, os vídeos, as figuras, gráficas, além das expressões faciais e corporais, todos esses recursos devem ser explorados e incorporados no ambiente da educação escolar dos alunos surdos.

Considerar condições de igualdade verdadeira para o surdo é aceitar a proposta do bilinguismo, essa abordagem educativa defende o acesso as duas línguas: a Língua Brasileira de sinais e a Língua Portuguesa na modalidade escrita, assim, o surdo estaria assistido em sua especificidade, compreendendo dessa forma que a proposta bilíngue é a melhor modalidade de ensino e aprendizagem para o educando surdo. Segundo Machado (2008):

Visualizar uma escola plural, em que todos que a integram tenham a "possibilidade de libertação", é pensar uma nova estrutura. Para tanto, é necessário um currículo que rompa com as barreiras sociais, políticas e econômicas e passe a tratar os sujeitos como cidadãos produtores e produtos de uma cultura [...] pouco adianta a presença de surdos se a escola ignora sua condição histórica, cultural e social. (MACHADO, 2008, p. 78)

A linguagem é um instrumento indispensável na comunicação dos seres humanos, ela é o contra ponto para se comunicar, produzir, desenvolver, compreender e interagir, as manifestações dos outros e as suas próprias, e a língua é o instrumento mais importante nesse processo. Sentir-se aceito, querido e reconhecido faz com que os alunos que apresentem algum tipo de 
deficiências sintam-se motivados a continuarem na escola, e o uso das línguas de sinais concretiza essa sensação para os surdos, pois assim enxergam como sendo também um ambiente seu. Portanto, para que aconteça, de fato, a inclusão escolar, devem acontecer mudanças e adaptações que atinjam a todos e não apenas aos educandos especiais, pois, direta ou indiretamente, fazem parte da vida escolar desses alunos, como afirma Mantoan ao dizer que:

[...] a inclusão escolar envolve basicamente, uma mudança de atitude face ao Outro: que não é mais um, um indivíduo qualquer, com o qual topamos simplesmente na nossa existência e com o qual convivemos certo tempo, maior ou menor de nossas vidas. O Outro é alguém que é essencial para nossa constituição como pessoa e dessa Alteridade é que subsistimos, e é dela que emana a Justiça, a garantia da vida compartilhada. (Mantoan, 2004, p. 81)

O professor tem que ser o mediador nesse processo não um transmissor de conhecimentos mas um sujeito que irá fazer da sala de aula um lugar mágico como bem aponta Paulo Freire ao dizer, "que ensinar não é transferir conhecimentos, mas criar as possibilidades para a sua própria produção ou a sua construção" (2001, p.52). Criar uma sala de aula com situações onde o aluno deve questionar, refletir e solucionar sozinho os desafios que se propuser é permiti-lo construir o seu próprio conhecimento, se tornando um sujeito crítico, ativo e participativo, capaz de se posicionar melhor na sociedade que Ihe espera.

\section{REFERÊNCIAS}

BRANDÃO, Carlos Rodrigues. O Que é Educação. São Paulo: Brasiliense 19955. 33를 (Coleção Primeiros Passos).

BRASIL. [Leis de Diretrizes e Bases da Educação Nacional (1996)] LDB: Lei de Diretrizes e Bases da Educação Nacional: Lei 9.394/1996-2.ed.- Rio de Janeiro: Lamparina, 2010.

BRASIL. Ministério da Educação. Secretaria de Educação Especial. Ensino de Língua portuguesa para surdos: caminhos para a prática pedagógica/ Secretaria de Educação Especial.- Brasília: MEC/SEESP,2002.

BRASIL. DECRETO n 5.626, DE 22 DE DEZEMBRO DE 2005 (Regulamenta a Lei $\mathrm{n}^{\circ}$ 10.436, de 24 de abril de 2002, que dispõe sobre a língua Brasileira de Sinais- Libras, e o art. 18 da Lei № 10.098. de 19 de dezembro de 2000.)

BRASIL. Senado Federal. Constituição da República Federativa do Brasil. Brasília, DF, 1988.

CAMARA JR., Joaquim Mattoso. Estrutura da Língua Portuguesa. - 43 ed., Petrópolis: Rio de Janeiro: Editora Vozes, 2011.

CAVALCANTE, Meire. A escola que é de todas as crianças. In: Nova Escola. № 182. Brasília; Abril, Maio/2005. 
DÁMAZIO Mirlene Ferreira Macedo. Atendimento Educacional Especializado para Pessoa com Surdez. São Paulo: MEC/SEESP, 2007.

DECLARAÇÃO DE SALAMANCA E ENGUADRAMENTO DA ACÇÃO. Na Área das necessidades educativas especiais: Conferência Mundial sobre NEE: Acesso e Qualidade - UNESCO

FELIPE, T. A. Escola Inclusiva e os direitos linguísticos dos Surdos. Rio de Janeiro: Revista Espaço - INES, 1997. p. 41-46, Vol. 7.

FREIRE, Paulo. Pedagogia da Autonomia: saberes necessários à pratica Educativa. Rio de Janeiro: Paz e Terra,1996.

FREIRE, Paulo. Pedagogia do oprimido. Rio de Janeiro: Paz e Terra, 1987, 28 ed.

GESSER, Audrei. LIBRAS? Que língua é essa ?: Crenças e preconceito em torno da língua de Sinais e da realidade surda. São Paulo : Parábola editorial,2009.

GIL, Antônio Carlos. Métodos e técnicas de pesquisa social. São Paulo: Atlas, 2008, 6 ? $^{\mathrm{a}}$ ed.

GODOY, A. S. Introdução à pesquisa qualitativa e suas possibilidades. In: Revista de Administração de Empresas. São Paulo: v.35, n.2, p. 57-63, abril 1995.

GROLLA, Elaine; SILVA, Maria Cristina Figueiredo. Para conhecer Aquisição da linguagem. - São Paulo: Contexto, 2014.

GUARINELLO, Ana Cristina. O papel do outro na escrita de sujeitos surdos. São Paulo: Plexus, 2007.

HONORA, Márcia; FRIZANCO, Mary Lopes Esteves. Esclarecendo as deficiências: aspectos históricos e práticos para contribuição com uma sociedade inclusiva. - São Paulo, SP: Ciranda Cultural Editora e Distribuidora Ltda., 2008.

HOUSSAIS, Antônio. O que é língua. 2 ed. São Paulo: Brasiliense. 1991.

JESUS, Saul Neves de. Educação Especial: em direção à educação inclusiva / organizadores Claus Dieter Stobaus, Juan José Mourifio Mosquera. - 2. ed. Porto Alegre : EDIPUCRS, 2004.

$\mathrm{KOCH}$, Ingedore Villaça e ELIAS, Vanda Maria. Ler e Compreender: os sentidos do texto- São Paulo: Contexto, 2009.

LODI, Ana C. B; LACERDA, C. B. F. de. Uma escola, duas línguas. Princípios para a educação de alunos surdos. RevistaFórum, Rio de Janeiro, v. 21, p. 25-31, jan.-jun. 2010.

LIBÂNIEO, José Carlos. Adeus professor, adeus professora: Novas exigências educacionais e profissão docente. São Paulo: Cortez, 1998. 
MACHADO, Fernanda de Camargo; LUNARDI-LAZZARIN, Márcia Lise. Formar, tolerar, incluir: tríade de governamento dos professores de surdos. In: LUNARDILAZZARIN, Márcia Lise;LOPES, Maura Corcini; MACHADO, Fernanda de Camargo(org.). Cadernos de Educação, Pelotas, ano 19, n. 36, p. 19-44, maioago. 2010.

MACHADO, P. C. (2008). A política educacional de integração/inclusão: um olhar do egresso surdo. Florianópolis, SC: UFSC.

MANTOAN, Maria Teresa Eglér. Inclusão escolar: pontos e contrapontos. São Paulo: Summus, 2006.

NUNES, A. I. ; Silveira, R.N. Psicologia da aprendizagem: processos, teorias e contextos, Fortaleza: Liber Livro, 2008. (Série Formar).

PEDREIRA, S. M. F. Porque a Palavra não adianta: Um Estudo das Relações entre Surdos/as e Ouvintes em uma Escola Inclusiva na perspectiva intercultural. Rio de Janeiro: Pontifícia Universidade Católica, 2006.

PEREIRA, M. C. C. O ensino de português como segunda língua para surdos: princípios teóricos e metodológicos. Educar em Revista, Curitiba, Brasil, Edição Especial n. 2/2014, p. 143-157. Editora UFPR.

QUADROS, Ronice Muller de; KARNOPP, Lodenir Becker. Língua de Sinais Brasileira - Estudos Lingüísticos, 2004. Ed 1. Artmed

QUADROS, R.M. Educação de Surdos: a aquisição da linguagem. Porto Alegre. Artes Médicas, 1997.

QUADROS, Ronice Muller de; KARNOPP, Lodenir Becker. Estudos Surdos I. Petrópolis: Arara Azul, 2006.

QUADROS, Ronice Müller de; SCHMIEDT, Magali L.P. Idéias para ensinar português para alunos surdos Brasília: MEC, SEESP, 2006. 120p.

SALLES, Heloisa Maria Moreira Lima; FAULSTICH, Enilde; CARVALHO, Orlene Lúcia; RAMOS, Ana Adelina Lopo. Ensino de Língua Portuguesa para Surdos, vol. 1 - caminhos para a pratica pedagógica, Programa Nacional de Apoio à Educação dos Surdos, 2004.

SAUSSURE, Ferdinand. Curso de Linguística Geral. São Paulo: Cultrix, 1970. SILVA, Marilia da Piedade Marinho. A construção de Sentido na Escrita do aluno Surdo/ Marilia da Piedade Marinho Silva. - São Paulo: Plexus Editora, 2001 